удК 351.85

Е. Г. Рогова

Иркутская областная филарлония, 2. Иркутск, Российская Федерация

Н. С. Хохлова

Байкальский государственный университет, 2. Иркутск, Российская Федерация

\title{
РОЛЬ ТЕХНОЛОГИИ ФАНДРЕЙЗИНГА В РАЗВИТИИ БЮДЖЕТНЫХ УЧРЕЖДЕНИЙ КУЛЬТУРЫ
}

\begin{abstract}
АНнОтАЦИЯ. Статья посвящена исследованию процесса использования технологии фандрейзинга в развитии концертных организаций, который рассматривается на примере отечественных филармоний. Выделена специфика экономики культуры, дана оценка современного финансирования сферы культуры, описана сущность фандрейзинга, как технологии. Предметом особого внимания авторов является анализ применения технологии фандрейзинга отечественными филармониями, этапы становления и развития данных учреждений на рынке культурных благ. Определена роль технологии фандрейзинга для перспективного роста привлечения ресурсов, позволяющая сохранять и развивать музыкальное искусство, как бесценный культурный потенциал развития общества.

кЛючЕВЫЕ СлОВА. Культура; учреждение культуры; филармония; фандрейзинг; спонсорство; эндаумент-фонд.

ИНФОРМАЦИЯ О СТАТЬЕ. Дата поступления 21 апреля 2017 г.; дата принятия к печати 18 мая 2017 г.; дата онлайн-размещения 19 июня 2017 г.
\end{abstract}

E. G. Rogova

Irkutsk Regional Philharmonic Society, Irkutsk, Russian Federation

N. S. Khokhlova Baikal State University, Irkutsk, Russian Federation

\section{ROLE OF FUNDRAISING TECHNOLOGY IN DEVELOPING BUDGETARY CULTURAL INSTITUTIONS}

ABSTRACT. The article is devoted to investigating the process of using the fundraising technology in developing concert organizations, which is examined in terms of national philharmonic societies. It identifies the specifics of economy of culture, makes evaluation of current financing of the cultural sphere, describes the essence of fundraising as a technology. The subject of authors' special attention is analysis of applying the fundraising technology by national philharmonic societies, stages of establishment and development of these institutions in the market of cultural benefits. It determines the role of fundraising technology for perspective growth of attracting resources that allow to to preserve and develop the musical art as an invaluable cultural potential for development of the society.

KEYWORDS. Culture; cultural institution; philharmonic society; fundraising; sponsorship; endowment fund.

ARTICLE INFO. Received April 21, 2017; accepted May 18, 2017; available online June 19, 2017.

Сохранение и развитие культуры в любом государстве является фундаментальной основой развития общества. В последние десятилетия в большинстве стран, в том числе и в Российской Федерации, данной проблеме уделяется много внимания. На самом высоком уровне подчеркивается актуальность использования такого важного ресурса, как культура, в том числе, в рамках формирования

(C) Е. Г. Рогова, Н. С. Хохлова, 2017

\section{Baikal Research Journal}


инновационной экономики. Еще в 1965 г. были опубликованы первые статьи, посвященные непосредственно экономике культуры. Основоположником экономики культуры является Уильям Джек Баумол (1922 г.), который в настоящее время является профессором Принстонского университета. В своей монографии «Исполнительские искусства: экономическая дилемма» (1966 г.) Баумол писал: «... что до него экономическая теория оперировала понятиями «фирма» и «цена», а Баумол обратил внимание, что как правило, издержки организаций занимающихся культурной деятельностью, многократно превосходят их доходы и эту разницу возможно компенсировать только за счет благотворителей. Кроме того, Баумол отметил, что подобное положение учреждений культуры не является эпизодическим или переходным, а оно перманентно, практически для большинства организаций, страдающих от «болезни издержек» [1]

Ричард Флорида в своей книге «Креативный класс» [2], описал культуру, как значимый экономический ресурс, а Дж. Пайн и Х. Гилмор в книге «Экономика впечатлений» [3] пишут о том, что на сегодняшний день, успех в экономике может быть достигнут только через творческий подход и творческий потенциал. Шведы К. А. Нордстрем и Й. Риддерстрале в книге «Бизнес в стиле фанк: Капитал пляшет под дудку таланта" [4] утверждают, что не только знания и информация, но и креативное видение стали решающими лидирующими преимуществами. В тоже время, Джон Хокинс утверждает, что особенность творчества заключается в том, что это универсальный, общечеловеческий талант и врожденная способность к таланту есть у всех, но не все могут производить креативные продукты [5].

Развитие культуры, приобщение общества к культурному и историческому наследию способствует развитию креативного мышления, творческого потенциала людей и как правило, росту инновационной экономики.

Несмотря на то, что Россия владеет огромным культурным потенциалом, этот потенциал до сих пор не используется в полном объеме. Бессистемные попытки внедрения государственных и муниципальных программ, нехваткой профессиональных специалистов, способных преодолевать «сопротивление внешней среды» и, конечно финансовые трудности, которые не дают возможности в полном объеме развернуть реформы в сфере культуры.

Сегодня отрасль культуры в большей части субъектов Российской Федерации представлена государственными учреждениями культуры, большая часть которых сохранила в себе старые, еще социалистические принципы существования и не стремятся, и не торопятся применить в своей работе опыт работы успешных учреждений культуры субъектов Российской Федерации, не говоря уже о зарубежном опыте.

К сожалению, традиционно, государственное финансирование сферы культуры номинально и по-прежнему складывается по остаточному принципу, а поэтому занимает последнюю строку в бюджете страны. Например, в период с 2008 по 2016 г. расходы консолидированного бюджета Российской Федерации на культуру и кинематографию несколько снизились и не превысили $0,55 \%$ к ВВП в 2016 г., по сравнению с 2008 г. финансирование составило 0,60 \% к ВВП ${ }^{1}$ (рис. 1).

По данным электронного портала «Гуманитарные технологии» ${ }^{2}$, по сравнению со странами входящими в организацию экономического сотрудничества и развития (ОЭСР), в которую входят 27 государств, Россия занимает 19 место по расходам на культуру и кинематографию ${ }^{3}$ (табл. 1 ).

\footnotetext{
${ }^{1}$ Федеральная служба государственной статистики [Электронный ресурс] : офиц. сайт. URL: http://www.gks.ru/.

${ }^{2}$ Индекс лучшей жизни. Гуманитарная энциклопедия [Электронный ресурс] / Центр гуманитар. технологий. URL: http://gtmarket.ru/research/oecd-better-life-index/info.

${ }^{3}$ URL: http://www.gks.ru/.
}

\section{Baikal Research Journal}




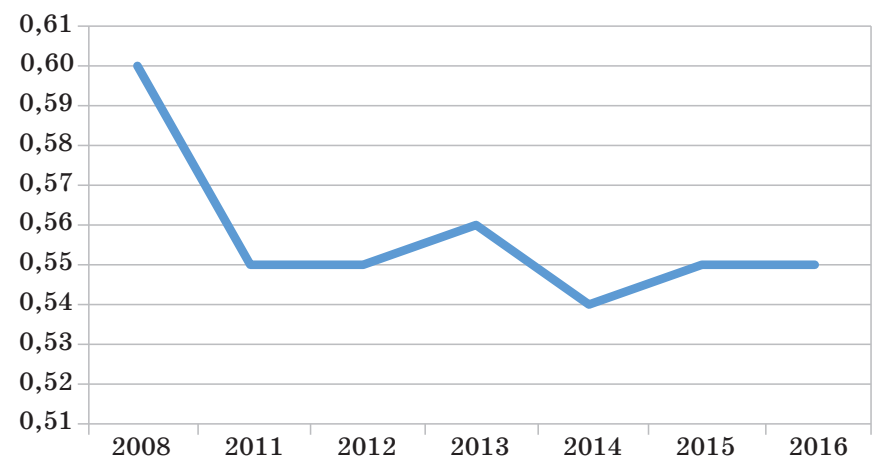

Рис. 1. Расходы консолидированного бюджета Российской Федерации на культуру и кинематографию, \% к ВВП

Таблица 1

Показатели рейтинга стран по государственныл расходал на культуру, \% ВВП

\begin{tabular}{|l|l|r|r|r|r|}
\hline Место в рейтинге & Государство & \multicolumn{1}{|c|}{2008} & \multicolumn{1}{|c|}{2010} & \multicolumn{1}{|c|}{2011} & \multicolumn{1}{|c|}{2012} \\
\hline 1 & Исландия & 1,36 & 1,25 & 1,16 & 1,16 \\
\hline \multicolumn{2}{|c|}{ Средний показатель по ОЭСР } & 0,68 & 0,68 & 0,65 & 0,64 \\
\hline 19 & Россия & 0,60 & 0,60 & 0,55 & 0,55 \\
\hline
\end{tabular}

Статистическая служба Европейского союза Евростат (англ. Eurostat) - занимающаяся сбором статистической информации) в 2014 г. опубликовала показатели расходов на культуру в расчете на душу населения среди стран ОЭСР. Российская Федерация в общем демонстрирует значительное отставание от того же показателя стран ОЭСР. Так, например, в России этот показатель равен 57 евро на человека в год и обогнала лишь Португалию, Румынию, Болгарию и Грецию. В тоже время этот показатель, например, в Норвегии составляет 447 евро, во Франции 252 евро, Германии 145 евро на человека в год.

Если еще не так давно, учреждения культуры находились на полном государственном обеспечении, то сейчас финансирование со стороны государства уменьшилось во много раз. С начала 1990 -х гг. обеспеченность населения страны услугами учреждений культуры значительно упала, снизилась их доступность и качество, особенно, для жителей небольших городов и сельской местности.

Доля бюджетного финансирования в общем объеме финансовых ресурсов учреждений культуры и искусства Российской Федерации в 2014 г. составила от 73 до $98 \%$, в зависимости от сферы деятельности учреждения культуры ${ }^{4}$. Отметим, что потенциал для увеличения внебюджетных доходов учреждения культуры не имеет безграничных возможностей (ограниченная пропускная возможность, увеличение стоимости услуг может привести к уменьшению доступности благ культуры и искусства для широких слоев населения).

Необходимо учитывать, что согласно основному закону нашей страны, каждый имеет право на участие в культурной жизни и пользование учреждениями культуры, на доступ к культурным ценностям ${ }^{5}$. При этом объем средств из иных источников, таких как благотворительность или спонсорские средства в общей доле финансовых ресурсов российских организаций культуры минимальны (табл. 2).

${ }^{4}$ О Стратегии государственной культурной политики на период до 2030 года [Электронный ресурс] : распоряжение Правительства РФ от 29 февр. 2016 г. № 326-р // СПС «КонсультантПлюс».

5 Конституция Российской Федерации : принята всенар. голосованием 12 дек. 1993 г. (ред. от 30 дек. 2008 г.) // Российская газета. 1993. 25 дек.

\section{Baikal Research Journal}


Сложившаяся ситуация говорит об обязательной разработке и принятию мер по минимизированию спада в развитии культуры, и в первую очередь, поиска спонсорских источников, пополняющих финансовые ресурсы учреждений культуры.

Таблица 2

\section{Структура финансовых поступлений учреждений культуры} и искусства РФ в 2014 г, \%

\begin{tabular}{|l|r|r|r|r|r|r|}
\hline \multicolumn{1}{|c|}{$\begin{array}{c}\text { Источники } \\
\text { финансирования }\end{array}$} & Театры & Музеи & $\begin{array}{l}\text { Концертные } \\
\text { организации }\end{array}$ & $\begin{array}{r}\text { Клубно-досуговые } \\
\text { учреждения }\end{array}$ & $\begin{array}{c}\text { Детские } \\
\text { школы } \\
\text { искусств }\end{array}$ & $\begin{array}{c}\text { Библио- } \\
\text { теки }\end{array}$ \\
\hline $\begin{array}{l}\text { Бюджетное финансиро- } \\
\text { вание }\end{array}$ & 73,1 & 80,2 & 78,6 & 91,2 & 91,1 & 98,0 \\
\hline $\begin{array}{l}\text { Благотворительные и } \\
\text { спонсорские средства }\end{array}$ & 1,2 & 2,2 & 0,9 & 1,0 & 5,1 & 0,6 \\
\hline
\end{tabular}

Успешный опыт учреждений культуры, таких как учреждение культуры Государственный академический Большой театр России; учреждение культуры Московская государственная академическая филармония; учреждение культуры Санкт-Петербургская академическая филармония им. Д. Д. Шостаковича и многих других известных учреждений, получивших мировое признание и внушительную спонсорскую поддержку, подтверждает, что данный источник имеет огромный потенциал пополнения бюджетов учреждений культуры.

Организация финансирования учреждений культуры должна включать в себя различные источники такие как: традиционное бюджетное финансирование, государственно-частное партнерство, гранты и спонсорские средства. Технологии привлечения средств для реализации социальных проектов из различных источников принято называть фандрейзингом (от англ. Fundraising - привлечение и аккумулирование средств из различных источников для реализации проектов и программ) [6].

Далее рассмотрим опыт использования технологии фандрейзинга среди концертных организаций отечественных учреждений культуры, в частности, филармоний. История многих российских филармоний начинает свой путь с $30-x$ гг. $\mathrm{XX}$ в. В те годы, в молодом советском государстве начали трансформироваться концертные агентства и бюро, которые были организованы еще во времена новой экономической политики. Их место достойно заняли филармонии (от греч. phileo - любить и harmonia - гармония, музыка) - музыкальное общество или учреждение, занимающееся организацией концертов, содействием развитию и пропагандой музыкального искусства) [7]. К 1975 г., в период СССР, насчитывалось 137 филармоний. После распада Советского союза деятельность филармоний происходила на фоне сложных процессов, охвативших экономическую, социальную и политическую сферу, государство утратило монополию на управление культурой. В начале 1990-х г. был принят Федеральный закон «Основы законодательства РФ о культуре» от 9 октября 1992 г. № 3612-1-ФЗ (в редакции от 28 ноября 2015 г.), который долгое время оставался единственным нормативным-правовым актом, регулирующим отношения в сфере сохранения и развития культуры в Российской Федерации. Уменьшение расходов финансирования концертных организаций, ухудшение материального положения привело к снижению интереса со стороны слушателей, падению престижности профессии с одной стороны, а с другой, к усилению самоорганизации культурных проектов, повышению автономности филармоний.

В концертных организациях пока еще достаточно низка доля участия бизнеса и населения в пополнении финансовых и материальных ресурсов, но становится актуальным вопрос привлечения новых форм пополнения бюджетов филармоний,

\section{Baikal Research Journal}

электронный научный журнал Байкальского государственного университета 
планирования и организации процессов сторонней поддержки, а соответственно и развития фандрейзинга.

В современной России в 85 субъектах насчитывается 84 филармонии, исключение составил Чукотский автономный округ, профессиональную культуру которого представляет эскимосский ансамбль «Эргырон», основанный в 1968 г. В течение июня - декабря 2016 г. авторами было проведено исследование деятельности концертных организаций России. Для дальнейшего рассмотрения 83 филармоний по теме использования технологии фандрейзинга был проведен опрос из 8 вопросов, целью которого является анализ использования технологии фандрейзинга в привлечении благотворительных и спонсорских средств отечественных филармоний. Филармония Республики Дагестан не участвовала в опросе, так как не предоставила информацию:

1. Дата основания филармонии.

2. Тип учреждения (автономный, бюджетный, казенный).

3. Наличие симфонического оркестра.

4. Определено ли лицо (отдел) ответственное за фандрейзинг.

5. С какого года введена технология фандрейзинга.

6. Определен ли бюджет доходов от фандрейзинга.

7. Разработана ли и описана процедура обращения за помощью.

8. Оформляется ли официально отношения Донор-Получатель.

Попытаемся проанализировать и обосновать каждый ответ на поставленные вопросы.

Исследование показало, что большинство филармоний РФ было основано в период с 1930 по 1950 г. (рис. 2).

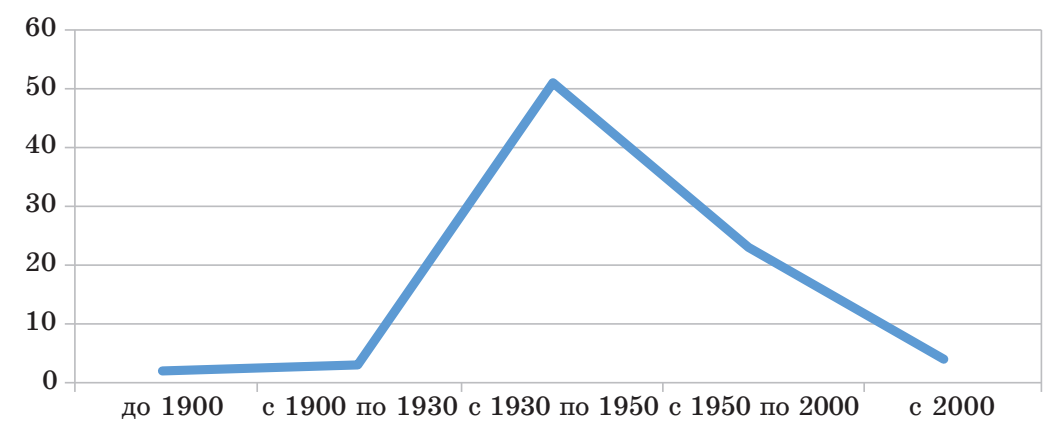

Рис. 2. Периоды основания филармоний в Российской Федерации

Пиковый период обусловлен неимоверным патриотическим настроем, становление молодого советского государства, далее Великая Отечественная война и конечно, тяжелые послевоенные годы восстановления. Старейшими филармониями по праву считаются филармония Орловской области и Кисловодская филармония, основанные до 1900 г. Новейшая история, к сожалению, не может похвастаться открытием большого количества концертных площадок, но те четыре филармонии, которые были построены и введены в эксплуатацию после 2000 г. (Республика Калмыкия, Пензенская область, Ханты-Мансийский АО, Ямало-Ненецкий АО) можно считать лучшими площадками в плане современной архитектуры, акустической, технической оснащенности.

Согласно Федеральному закону «О внесении изменений в отдельные законодательные акты Российской Федерации в связи с совершенствованием правового положения государственных (муниципальных) учреждений» от 8 мая 2010 г. № 83 Ф3 в зависимости типа собственника выделяют три вида учреждений: госу-

\section{Baikal Research Journal}


дарственные, частные и муниципальные. В свою очередь, как государственные, так и муниципальные организации могут подразделяться на казенные, автономные и бюджетные. В классификации по типу учреждений преобладают автономные учреждения культуры 55,4 \% (46 филармоний), на втором месте бюджетные учреждения культуры 44,6 \% (37 филармоний), казенных учреждений культуры среди филармоний не представлено.

Очень важный вопрос, о наличии в филармонии симфонического оркестра. Симфонический оркестр - это своего рода индикатор финансовой, технической оснащенности, профессиональных кадров, статуса филармонии, туристической привлекательности региона, который выделяет его среди всех остальных филармоний. Как правило, большинство симфонических оркестров - это достаточно большие коллективы, от 50 до 100, а иногда и более человек, содержание которых может себе позволить не каждый субъект. Среди исследуемых филармоний наличие симфонического оркестра есть только в 46 учреждениях $(55,4 \%)$, остальные филармонии, позиционируют свою основную концертную деятельность программами хоровых капелл, ансамблями русских-народных инструментов, ансамблями духовых инструментов, детскими, студенческими коллективами и др.

На вопрос, о наличии специалиста, сотрудника, отвечающего за фандрейзинговую деятельность филармонии, не было получено доминирующего ответа. Для большинства филармоний, данная технология - относительно новый вид деятельности, но при этом хочется отметить, что в 37 , филармониях $(44,6 \%)$ определено лицо (в основном специалист по PR), в 32 учреждениях $(38,6 \%$ ) нет конкретного сотрудника, занимающегося фандрейзинговой деятельностью, и привлечение финансовых ресурсов носит стихийный характер. В 11 филармониях $(13,3 \%)$ существует целый отдел, осуществляющий фандрейзинговую деятельность и только в трех учреждениях $(3,5 \%)$ успешно действуют службы по развитию филармоний. Это, конечно, Московская филармония, Санкт-Петербургская филармония и Свердловская филармония, - в данных учреждениях фандрейзиноговой деятельностью занимаются более 10 лет. В 50,6 \% филармоний привлечением спонсорских средств занимаются от 5 до 10 лет, в 42,2 \% менее 5 лет и только в 7,2 \% более 10 лет (к выше перечисленным трем филармониям относятся Костромская филармония, Тольяттинская филармония, и Тюменская филармония). Бюджет от доходов фандрейзинговой деятельности определен в 38 \% учреждений, в остальных $62 \%$ привлечение средств несет стихийный характер, в виде разовых акций и редких финансовых поддержек.

Среди всех филармоний, занимающихся фандрейзинговой деятельностью процедура обращения за помощью документально разработана и описана у $41 \%$ учреждений, у $49,3 \%$ нет прописанной технологии и у $9,6 \%$ на стадии рассмотрения. При этом, в 84,3 \% случаев отношения Донор-Получатель официально оформляются в письменной форме, если Даритель является юридическим лицом и стоимость дарения превышает 3000 р. В остальных 15,7 \% филармоний спонсорская помощь остается без оформления и не попадает под бухгалтерский учет, что является нарушением инструкции Минфина России от 1 декабря 2010 г. № 15 и № 183 н [8].

Среди концертных организаций Сибирского Федерального округа (СФО) заслуживают внимания филармонии Томской области, Новосибирской области, Омской области, Красноярского края, Иркутской и Кемеровской областей. В данных субъектах филармонии имеют давнюю историю, они основаны в 30-40 гг. XX в. В 8 из 12 субъектов СФО на базе филармоний работают симфонические оркестры, 9 из 12 филармоний являются автономными учреждениями культуры. Стоит отметить, что сфера культуры ни в одной стране мира не формируется исключительно толь-

\section{Baikal Research Journal}


ко на дотации государственного бюджета или только на средства коммерческого сектора. Культура может жить и формироваться только в сочетании государственной поддержки и привлечении средств из других источников. По словам первого заместителя директора Института экономики РАН А. Рубинштейна, данная задача решается не просто к введению многоканальной системы, переходом к программно-целевому и проектному финансированию, но и к расширению экономической самостоятельности организаций культуры. Многоканальная система поддержки учреждений культуры основывает стабильность ее развития.

В этом отношении считается актуальным и своевременным внедрение в практику системы эндаумент-фондов (эндаумент (англ. endowment) - целевой фонд, предназначенный для использования в некоммерческих целях, как правило, для финансирования учреждений образования, медицины, культуры) ${ }^{6}$. Для учреждений культуры эндаумент-фонды - это инновационная модель финансирования. История их существования начинается с Фонда Нобеля, которой основан на завещании Альфреда Нобеля 29 июня 1990 г., а его применение, на сегодняшний день, широко распространено за рубежом.

В практике отечественных учреждений культуры такие фонды находятся на пути своего развития, а вступивший в силу Федеральный закон «О порядке формировании и использовании целевого капитала некоммерческих организаций» от 30 декабря 2006 г. № 275-ФЗ (в редакции от 23 июля 2013 г.) (далее - Ф3 № 275), открыл и стимулировал в нашей стране создание эндаумент-фондов или фондов целевого капитала.

По сведениям некоммерческого партнерства организаций, выделяющие гранты «Форум доноров», к 2014 г. в России официально было зарегистрировано около 130 эндаумент-фондов. Большая часть фондов уже сформировали свой целевой капитал, остальные эндаумент-фонды находятся в состоянии привлечения средств, общий объем капитала фондов составляет более 25 млрд р. Большинство эндаумент-фондов сформированы для развития сферы науки и образования (71\%), пилотным фондом в марте 2007 г. стал эндаумент-фонд МГИМО. Лидером по созданию эндаумент-фонда в сфере культуры Сибирского федерального округа стал Омский областной музей изобразительных искусств им. М. А. Врубеля. Формирование эндаумент-фонда позволит прогнозировать будущее учреждений культуры в долгосрочной перспективе, - за счет устойчивого механизма финансирования в рамках государственно-частного партнерства.

Приоритетом эндаумент-фонда является прозрачный характер его деятельности. Схема формирования фонда проста: жертвователи осуществляют благотворительные вклады, формируя и пополняя эндаумент-фонд в порядке и целях, которые предусмотрены Ф3 № 275 , фонд передает средства в доверительное управление - акционерному обществу, обществу с ограниченной (дополнительной) ответственностью. Далее полученный доход распределяется на финансирование деятельности учреждения культуры (собственника целевого капитала). Некоммерческая организация не в праве использовать эти финансовые ресурсы. Согласно ФЗ № 275 некоммерческая организация в течении одного года должна сформировать фонд, сумма капитала которого составит не менее 3 млн р., в данном случае эндаумент-фонд считается сформированным. В будущем поступление новых средств благотворителей идут на пополнение уже образованного эндаумент-фонда. Данные финансовые ресурсы не расходятся одномоментно, а аккумулируют доход и питают проекты и программы на протяжении многих лет.

${ }^{6}$ URL: http://dic.academic.ru/dic.nsf/ruwiki/239274/.

\section{Baikal Research Journal}

электронный научный журнал Байкальского государственного университета 
Доход от использования фонда целевого капитала позволяет гарантировать частичную независимость учреждений культуры от разовых финансовых вливаний и стихийных поступлений за счет получения стабильного ежегодного дохода от управления эндаумент-фонда. Благотворительность в эндаумент-фонд - это проявление наивысшей оценки доверия благотворителя к учреждению культуры. Финансовые ресурсы, поступающие в эндаумент-фонд и доходы от управления целевым капиталом не облагаются налогом, а для физических лиц, вносящих пожертвования в целевой капитал, предусмотрен налоговый вычет из подоходного налога.

По данным официального портала Иркутской области культура субъекта представлена широкой сетью государственных и муниципальных учреждений, в 2015 г. действовало 1258 учреждений (табл. 3).

Таблица 3

Состав бюджетных учреждений культуры Иркутской области в 2015 2.

\begin{tabular}{|l|r|}
\hline \multicolumn{1}{|c|}{ Тип бюджетного учреждения культуры } & Количество, ед. \\
\hline Театры & 10 \\
\hline Концертные организации & 3 \\
\hline Музеи & 48 \\
\hline Библиотеки & 263 \\
\hline Клубно-досуговые учреждения & 814 \\
\hline Детские школы искусств & 102 \\
\hline Учеждения среднего профессионального образования & 5 \\
\hline Иные & 13 \\
\hline
\end{tabular}

На сегодняшний день для поддержки учреждений культуры в Иркутской области официально не зарегистрирован ни один специализированный эндаумент-фонд. Создание первого в Иркутской области фонда целевого капитала чрезвычайно важная задача, так как за первым фондом обязательно последует второй и третий, и т. д. На все учреждения культуры невозможно в полном объеме выделить бюджетные средства. И в этой ситуации формирование целевого капитала позволит обеспечить устойчивое развитие, независимость от редких случайных пожертвований, установит финансовую стабильность посредством получения гарантированного дохода, так как будущее культуры закладывается уже сегодня [9].

Формирование целевого капитала - важная часть регенерации субъекта. Развитие культуры создаст платформу для креативной деятельности, открывает для субъекта возможность устойчивого развития, обеспечивающего непрерывность и связь поколений, в частности, благодаря тому, что подход с позиций культуры становится неотъемлемым элементом всех проектов развития региона. Высокие эстетические качества и уровень сохранности исторического облика Иркутской области содействуют особой инвестиционной привлекательности, что способствует решению социально значимых проблем: снижение оттока населения, особенно молодежи, увеличение количества рабочих мест, сокращение уровня преступности среди подростков и молодежи, поддержка реставрационных и восстановительных работ, повышение качества жизни горожан и сельского населения. Стабильно развивающиеся учреждения культуры станут достоянием и гордостью всех жителей Иркутской области.

В открытом доступе, в сети интернет и в средствах массовой информации необходимо пояснять жителям области и другим заинтересованным физическим и юридическим лицам ценность общественных и инвестиций частного бизнеса в экономику культуры для того, чтобы бизнес и городское сообщество осознали әффективность и в некотором смысле элитарность инвестиций в культурно-историческое достояние, в развитие культурного туризма, в духовно-нравственную основу развития личности и общества. Важными связующими элементами, воздей-

\section{Baikal Research Journal}

электронный научный журнал Байкальского государственного университета 
ствующие на привлекательность Иркутской области, являются его культурные компоненты, такие как изобразительное искусство, архитектура (историческая часть), история, религия, музыка. Проведение ежегодных музыкальных фестивалей на различных площадках г. Иркутска и области являются одними из самых привлекательных и массовых мероприятий. Многие успешные территории в России используют музыкальные фестивали, как площадки, в первую очередь, народного единения, патриотического воспитания, продвижения и позиционирования своей территории, улучшения имиджа и повышения ее авторитета. Музыка - это ключевой компонент местной аутентичности, так как музыка играет центральную роль в формировании индивидуальности и характера общества.

Иркутская музыкальная жизнь тоже очень богата музыкальными фестивалями разных жанров и исполнителей. Начиная от крупных и международных, таких как фестиваль оперной музыки «Дыхание Байкала», фестиваль классической музыки «Звезды на Байкале», областной фестиваль органной и камерной музыки, джазовые фестивали, фестиваль «Музыка моего города», областной Пасхальный фестиваль «Повсюду благовест звучит», фольклорные фестивали и др. Инициатор и идейный вдохновитель, Народный артист РФ, Почетный гражданин г. Иркутска Денис Мацуев, при поддержке Министерства культуры и архивов Иркутской области, благотворительного Фонда Юрия Тена в рамках Международного фестиваля классической музыки «Звезды на Байкале» ежегодно проводит благотворительный аукцион «Нота До». Благотворительный Фонд, основанный в 1996 г., по инициативе Юрия Михайловича Тена не является специализированным фондом, поддерживающим исключительно проекты и мероприятия сферы культуры, на счету Фонда немало добрых дел в области образования и здравоохранения.

За все время проведения фестиваля, начиная с 2008 г., который призван помочь юным талантливым художникам и музыкантам, архитекторам и танцорам, около 600 детей приняли в дар концертные музыкальные инструменты, ноутбуки, инструменты для художественного творчества, а также получили возможность участия в Международных музыкальных конкурсах и фестивалях, благодаря собранным средствам аукциона «Ноты До».

На аукционе 2013 г. организаторы «Ноты До» собрали рекордную сумму почти в 13 млн р., по словам Дениса Мацуева «Россия всегда была знаменита своими меценатами, это благотворители, которые понимают, что одаренным детям, участникам ежегодного фестиваля «Звезды на Байкале» так необходима поддержка и успешное начало творческого пути». За всю историю проведения благотворительного аукциона удалось привлечь более 50 млн р. Сохранение и развитие музыкального искусства способствует популяризации Байкальского региона не только в Российской Федерации, но и за рубежом.

Музыкальные и историко-культурные ресурсы Иркутской области представляют большой интерес для гостей нашего региона, но на данный момент историческая среда, концертные организации, в частности органный зал Иркутской областной филармонии, колледж им. Ф. Шопена, клубно-досуговые учреждения муниципальных образований нуждаются в срочной реставрации и реконструкции. Учреждения культуры области ежегодно испытывают секвестирование своих бюджетов, а это на прямую отражается на качестве и количестве выпускаемых программ и концертов. Гастроли по области Губернаторского симфонического оркестра Иркутской областной филармонии, камерного хора филармонии, театральных трупп, музыкального лектория становятся большой редкостью в муниципальных образованиях, сельских поселениях. Материально-техническая база клубно-досуговых учреждений нищает и по большому счету, функционирует благодаря инициативе и поддержке самих жителей сел и деревень.

\section{Baikal Research Journal}

электронный научный журнал Байкальского государственного университета 
Большое количество факторов тормозящие развитие культуры в регионе, высокие требования предъявляемые к культурным продуктам, низкий профессиональный уровень сотрудников учреждений культуры, а чаще всего и острую нехватку, особенно в отдаленных районах говорят о том, что эндаумент-фонды могут стать устойчивым ресурсом формирования бюджета учреждений культуры, способствуют уверенной реализации проектов, расширения гастрольной деятельности музыкальных коллективов, что активно способствует повышению профессионального мастерства исполнителей, насыщению и удовлетворению населения области культурными продуктами. Осуществление формирования фонда целевого капитала в большей степени зависит от позиционирования профессиональной среды работников учреждений культуры, от ее способности к самосовершенствованию, самообразованию, желанию обучаться, работать в команде, возможности оказывать влияние на общественное мнение, объединенные общей целью поднять свое учреждение культуры на высокий профессиональный уровень, донося до общества реальный потенциал и актуализируя свой профессионализм на всех уровнях. Все эти качества дают возможность устойчивых контактов, развития социального партнерства, успешного фандрейзинга, а значит и формированию эндаумент-фондов.

\section{Список использованной литературы}

1. Baumol W. J. Performing Arts: The Economic Dilemma / W. J. Baumol, W. G. Bowen. New York : The Twentieth Century Fund, 1966. - 582 p.

2. Флорида Р. Креативный класс: люди, которые меняют будущее / Р. Флорида. M. : Классика-XXI, 2005. - 430 c.

3. Пайн Дж. Б. Экономика впечатлений: работа - это театр, а каждый бизнес - сцена / Дж. Б. Пайн, Дж. Х. Гилмор. - М. : Вильямс, 2005. - 304 с.

4. Нордстрем К. А. Бизнес в стиле фанк: Капитал пляшет под дудку таланта / К. А. Нордстрем, Й. Риддерстрале. - СПб. : Стокгольм. шк. экономики в Санкт-Петербурге, 2005. -288 c.

5. Хокинс Дж. Креативная экономика. Как превратить идеи в деньги / Дж. Хокинс. М. : Классика-XXI, 2011. - 256 с.

6. Артемьева Т. В. Фандрейзинг: привлечение средств на проекты и программы в сфере культуры и образования : учеб. пособие / Т. В. Артемьева, Г. Л. Тульчинский. - СПб. : Лань, 2010. - 284 с. - (Учебники для вузов. Специальная литература).

7. Толковый словарь русского языка : в 4 т. / под ред. Д. Н. Ушакова. - М. : Гос. изд-во иностр. и нац. словарей, 1940. - Т. 4. - 754 с.

8. Орлова Н. Может ли автономное учреждение получать спонсорскую и благотворительную помощь / Н. Орлова // Справочник руководителя учреждения культуры. 2016. - № 6. - C. 45-46.

9. Колодина Е. А. Зарубежная и российская практика применения механизмов публично-частного партнерства в сфере культуры / Е. А. Колодина // Публичное управление и территориальное развитие: тенденции, проблемы, перспективы мирового кризиса : сб. материалов Междунар. науч.-практ. конф. - Иркутск : Изд-во БГУЭП, 2015. - C. 12-22.

\section{References}

1. Baumol W. J., Bowen W. G. Performing Arts: The Economic Dilemma. New York, The Twentieth Century Fund, 1966. 582 p.

2. Florida Richard. The Rise of The Creative Class and How It's Transforming Work, Leisure, Community and Everyday Life. New York, Basic Books, 2002. 430 p. (Russ. ed.: Florida Richard. Kreativnyi klass: lyudi, kotorye menyayut budushchee. Moscow, Klassika-XXI Publ., 2005. 430 p.).

3. Pine Joseph B., Gilmore James H. The Experience Economy: Work Is Theater and Every Business a Stage. Harvard Business Press, 1999. 254 p. (Russ. ed.: Pain J. B., Gilmor J. H. Ekonomika vpechatlenii: rabota - eto teatr, a kazhdyi biznes - stsena. Moscow, Vil'yams Publ., 2005. 304 p.).

\section{Baikal Research Journal}

электронный научный журнал Байкальского государственного университета 
4. Nordstrцm Kjell A., Ridderstrele Jonas. Funky Business: Talent Makes Capital Dance. Stockholm, 1999. 210 p. (Russ. ed.: Nordstrцm Kjell A., Ridderstrele Jonas. Biznes $v$ stile fank: Kapital plyashet pod dudku talanta. Stockholm School of Economics in Saint Petersburg Publ., 2005. 288 p.).

5. Howkins John. The Creative Economy: How People Make Money from Ideas. London, Allen Lane, 2001. 263 p. (Russ. ed.: Howkins John. Kreativnaya ekonomika. Kak prevratit' idei $v$ den'gi. Moscow, Klassika-XXI Publ., 2011. 256 p.).

6. Artemyeva T. V. Fandreizing: privlechenie sredstv na proekty i programmy $v$ sfere kul'tury $i$ obrazovaniya [Fundraising: attraction of funds for projects and programs in the sphere of culture and education]. Saint Petersburg, Lan' Publ., 2010. 284 p.

7. Ushakov D. N. (ed.). Tolkovyi slovar' russkogo yazyka [Explanatory Dictionary of the Russian Language]. Moscow, State Publishing House of Foreign and national dictionaries Publ., 1940. Vol. 4. 754 p.

8. Orlova N. Can an autonomous institution receive sponsor and charity support? Sprav ochnik rukovoditelya uchrezhdeniya kul'tury $=$ Reference Book for Manager of Cultural Institution, 2016, no. 6, pp. 45-46. (In Russian).

9. Kolodina E. A. Foreign and Russian practice of applying mechanisms of public-private partnership in cultural sphere. Publichnoe upravlenie i territorial'noe razvitie: tendentsii, problemy, perspektivy mirovogo krizisa. Materialy Mezhdunarodnoi nauchno-prakticheskoi konferentsii [Public management and territorial development: trends, problems, prospects of world crisis. Materials of International Research Conference]. Irkutsk, Baikal State University of Economics and Law Publ., 2015, pp. 12-22. (In Russian).

\section{Информация об авторах}

Рогова Елена Геннадьевна - заместитель директора Органного зала, Иркутская областная филармония, 664003, г. Иркутск, ул. Дзержинского, 2, e-mail: rogova.elena@gmail.ru.

Хохлова Наталья Сергеевна - кандидат экономических наук, доцент, кафедра экономики и государственного управления, Байкальский государственный университет, 664003, г. Иркутск ул. Ленина, 11, e-mail: nshohlova@yandex.ru.

\section{Authors}

Elena G. Rogova - Assistant Director of Organ Hall, Irkutsk Regional Philharmonic Society, 2 Dzrezhinsky St., 664003, Irkutsk, Russian Federation; e-mail: rogova.elena@gmail.ru.

Natalya S. Khokhlova - PhD in Economics, Associate Professor, Chair of Economics and Public Administration, Baikal State University, 11 Lenin St., 664003, Irkutsk, Russian Federation; e-mail: nshohlova@yandex.ru.

\section{Библиографическое описание статьи}

Рогова Е. Г. Роль технологии фандрейзинга в развитии бюджетных учреждений культуры / Е. Г. Рогова, Н. С. Хохлова // Baikal Research Journal. — 2017. — T. 8, № 2. DOI: $10.17150 / 2411-6262.2017 .8(2) .15$.

\section{Reference to article}

Rogova E. G., Khokhlova N. S. Role of fundraising technology in developing budgetary cultural institutions. Baikal Research Journal, 2017, vol. 8, no. 2. DOI: 10.17150/24116262.2017.8(2).15. (In Russian).

\section{Baikal Research Journal}

